\title{
Off-label use of hormones as an antiaging strategy: a review
}

\author{
This article was published in the following Dove Press journal: \\ Clinical Interventions in Aging \\ 23 July 2014 \\ Number of times this article has been viewed
}

\author{
Nikolaos Samaras' \\ Maria-Aikaterini \\ Papadopoulou ${ }^{2}$ \\ Dimitrios Samaras ${ }^{3}$ \\ Filippo Ongaro' \\ 'Clinique Générale Beaulieu, \\ Geneva, Switzerland; ' 2 Department \\ of Internal Medicine, Rehabilitation \\ and Geriatrics, Geneva University \\ Hospitals, Geneva, Switzerland; \\ ${ }^{3}$ Department of Medical Specialties, \\ Clinical Nutrition, Geneva University \\ Hospitals, Geneva, Switzerland
}

\begin{abstract}
Given demographic evolution of the population in modern societies, one of the most important health care needs is successful aging with less frailty and dependency. During the last 20 years, a multitude of anti-aging practices have appeared worldwide, aiming at retarding or even stopping and reversing the effects of aging on the human body. One of the cornerstones of anti-aging is hormone replacement. At present, women live one third of their lives in a state of sex-hormone deficiency. Men are also subject to age-related testosterone decline, but andropause remains frequently under-diagnosed and under-treated. Due to the decline of hormone production from gonads in both sexes, the importance of dehydroepiandrosterone (DHEA) in steroid hormone production increases with age. However, DHEA levels also decrease with age. Also, growth hormone age-associated decrease may be so important that insulin growth factor-1 levels found in elderly individuals are sometimes as low as those encountered in adult patients with established deficiency. Skin aging as well as decreases in lean body mass, bone mineral density, sexual desire and erectile function, intellectual activity and mood have all been related to this decrease of hormone production with age. Great disparities exist between recommendations from scientific societies and actual use of hormone supplements in aging and elderly patients. In this article, we review actual data on the effects of age related hormone decline on the aging process and age-related diseases such as sarcopenia and falls, osteoporosis, cognitive decline, mood disorders, cardiovascular health and sexual activity. We also provide information on the efficiency and safety of hormone replacement protocols in aging patients. Finally, we argue on future perspectives of such protocols as part of everyday practice.
\end{abstract}

Keywords: Anti-aging, dehydroepiandrosterone, growth hormone, testosterone, estrogen, progesterone

\section{Introduction}

Antiaging medicine is a growing medical industry. The definition given by Binstock ${ }^{1}$ for antiaging medicine is the following: "measures taken in order to slow, stop or even reverse phenomena related to aging, as well as to increase life span". Various societies worldwide claim to have developed strategies against age-related diseases but also the aging process per se. One of the most important is the American Academy of Anti-aging Medicine, counting more than 26,000 members. Antiaging medicine was valued at around $\$ 20$ billion in 2002 worldwide and constitutes an extremely fast-growing industry. ${ }^{2}$

Successful aging is one of the most important needs of our fast-aging population. At present, worldwide numbers of people aged $>60$ years and $>80$ years reach 671 million and 80 million, respectively. Aging of the population is even more important in "developed" countries. Indeed, $21 \%$ of the European population and $17 \%$ of the North American population is aged $>60$ years. $^{2}$ When people aged $>80$ years are considered, half of them live in Europe and North America. These numbers are 
expected to rapidly grow. Estimates made by the United Nations World Population Prospects: The 2006 Revision (http://www.un.org/esa/population/publications/wpp2006/ WPP2006 Highlights rev.pdf) put the worldwide number of people aged $>60$ years and $>80$ years around 2 billion and 400 million, respectively, for $2050 .^{2}$ Therefore, the increase of the number of patients who will be referred to antiaging and geriatric programs is something to be expected. Perhaps the search for eternal youth will remain "factitious". Nevertheless, most antiaging programs and clinics also seek to implement strategies for successful aging and disease prevention. Nobody could claim that successful aging is not an absolute necessity for our aging societies.

One of the cornerstones of antiaging practices is hormone replacement. Hormone decrease with age is common and is related to decreased secretion from the pituitary gland, adrenals, and gonads. ${ }^{3}$ Skin aging as well as decreases in lean body mass, bone mineral density (BMD), sexual desire and erectile function, intellectual activity, and mood have all been related to this decrease in hormone production with age. ${ }^{3-5}$ This has led to the rather wide off-label use of hormone supplements in order to help reverse the effects of aging and improve quality of life. Unfortunately, studies on specific indications, long-term effects, and risks of such practices are lacking. In this article we will review actual data on the most frequently used hormones in antiaging medicine, their relationship with age-related diseases, and the safety of hormone supplementation protocols.

\section{Estrogens and progestins}

Symptoms of menopause such as vasomotor symptoms or vaginal dryness and reduced sexual pleasure affect twothirds of women during perimenopause. ${ }^{6,7}$ In 10\%-15\% of cases the intensity of symptoms is such that they interfere with daily activities and sleep. ${ }^{7}$ Demand for treatments that may reduce such symptoms is important. Estrogens alone or together with progesterone can relieve climacteric symptoms, increase quality of life, and prevent or even reverse vaginal atrophy. Despite estrogens' positive effects on symptoms, as well as on bone loss and colorectal cancer risk, ${ }^{8-11}$ the Women's Health Initiative (WHI) study ${ }^{12}$ showed a higher risk for breast cancer, stroke, cardiovascular disease, and thromboembolic events with combined treatment of estrogens and progestin. Nevertheless, several positive effects of hormone replacement therapy (HRT) were observed in this study. For instance, the combination of estrogen and progestin reduced by one-third the rates of hip and clinical vertebral fractures. Endometrial cancer rates were not influenced by the treatment, whereas colorectal cancer rates were reduced by $37 \%$. Total cancer incidence was not affected. In women with unopposed estrogen treatment, breast cancer risk did not increase.

The WHI study influenced overall prescription of HRT, notwithstanding that it used a very specific combination and dosage of conjugated equine estrogens and medroxyprogesterone acetate. It is therefore far from certain that the study's findings apply to lower dosages or other hormone formulations. ${ }^{13}$

Following these results, actual guidelines recommend that HRT be used at the lowest dose for the shortest amount of time. The US Food and Drug Administration proposes HRT only for vaginal dryness and hot flashes. ${ }^{14}$ Due to positive effects on bone, it may also be used exceptionally for the prevention of osteoporosis when other treatments are considered inappropriate. ${ }^{8,15}$

Physicians and patients have become extremely reluctant concerning HRT following the WHI study. Numbers of HRT prescriptions in the US rose from 58 million in 1995 to 90 million in 1999, corresponding to 15 million women per year. Numbers remained stable through to 2002. Within 3 months after publication of the results of the WHI study, prescriptions of various formulations of combined estrogens and progesterone dropped by $33 \%$ to $66 \% .{ }^{13}$ On the other hand, it has been estimated that $30 \%$ of women turn to alternative therapies to treat menopausal symptoms. ${ }^{16}$ Nowadays, multiple sites and books promote more natural ways for HRT using "bioidentical" products. Women worldwide are subject to increasing publicity on bioidentical estradiol, the less potent estrogen estriol, and bioidentical progesterone.

There is no standardized definition for the term "bioidentical". ${ }^{17}$ Bioidentical hormones are supposed to have the same molecular structure as endogenous hormones found in humans. They are most frequently produced from plants (mostly soy or yams) and are biochemically altered to be identical to hormones found in the body. ${ }^{8}$ They include estradiol, estrone, estriol, and progesterone and exist as compounded products or in regular approved drugs. Two other groups of estrogens are used in HRT and are considered to be nonbioidentical: natural estrogens found in the urine of pregnant mares (estrone sulfate and equilin sulfate) and synthetic estrogens (ethinyl estradiol and quinestrol). ${ }^{8}$ Synthetic progestins mostly used worldwide include medroxyprogesterone acetate (most frequently used in the US), norethidrone acetate, cyproteron acetate, norgestimate, norgestrel, and dydrogesterone. 


\section{Estradiol}

Estradiol is the most potent estrogen in women. Bioidentical estradiol is available in pills, patches, transdermal formulations, and vaginal gels. Various factors influence the efficiency and safety profile of estradiol, such as administration route, posology, age at which treatment was initiated, as well as the type of progestin used in combination. ${ }^{8,18}$ In general, transdermal estradiol formulations seem as effective as oral formulations, but studies have shown better safety profiles. First, concerning thromboembolism risk, transdermal estradiol avoids the "first-pass" effect, thus minimizing the induction of clotting factors by the liver. It therefore seems to have a lower risk for thromboembolism than oral estrogens. ${ }^{19,20}$ Concerning cardiovascular risk safety, the first-pass effect also appears to be associated with better lipid profiles. ${ }^{19}$ Oral estrogen formulations would also be responsible for the production of angiotensinogen by the liver. Nevertheless, an increased risk for high blood pressure with oral formulations or a beneficial effect of transdermal estradiol on blood pressure has not been confirmed in clinical studies..$^{19,21}$ Moreover, transdermal estradiol improved endothelial function in postmenopausal women with coronary artery disease when compared with placebo. ${ }^{22}$ Finally, transdermal estradiol formulations seem to have a better effect on the prevention of atherosclerosis. ${ }^{23}$ Of course, concerning cardiovascular risk, timing of HRT introduction is crucial, and positive effects are mostly observed when treatment is introduced around perimenopause. ${ }^{19}$

Concerning breast cancer, WHI showed an increased risk only in the group where estrogens were combined with progestins, whereas unopposed estrogen treatment was not related to an increase of breast cancer risk. ${ }^{12}$ Concerning opposed treatment, observational data support a better safety profile for breast cancer with the combination of bioidentical estradiol and bioidentical progesterone compared with the combination used in the WHI study (conjugated equine estrogen and medroxyprogesterone acetate). ${ }^{19}$ Also, transdermal estradiol formulations have been related to better safety profiles than oral formulations. ${ }^{24}$ In fact, various estrogen metabolites have different effects on breast cancer risk. 4-Hydroxyestrogens and $16 \alpha$-hydroxyestrone are related to a higher risk, whereas 2-methoxyestradiol has mostly anticarcinogenic effects. ${ }^{25}$ Oral estrogen formulations have been related to higher levels of potentially toxic estrogen metabolites compared with transdermal estradiol. ${ }^{26} \mathrm{Nevertheless,} \mathrm{others} \mathrm{found} \mathrm{no}$ differences between estradiol administration routes and the risk for breast cancer. ${ }^{27,28}$

\section{Estriol}

Estriol is widely used in antiaging medicine as an HRT. Estradiol is reversibly transformed to estrone. ${ }^{6}$ On the other hand, estriol is the irreversible end product of estradiol and estrone metabolism. ${ }^{8}$ There are two kinds of estrogen receptors (ERs) in tissue, ER- $\alpha$ and ER- $\beta$. Estradiol has equally high affinity for both. Estrone, on the other hand, has a lower overall affinity than estradiol but is still rather high (around two-thirds of estradiol's affinity for ER- $\alpha$ and one-third for ER- $\beta$ ). Estriol is a weaker estrogen with only one-seventh of estradiol's affinity for ER- $\alpha$ and one-fifth for ER- $\beta$. ER- $\alpha$ receptors are mostly encountered in the ovaries, the endometrium, and breast cancer cells, whereas ER- $\beta$ is mostly found in the intestine, kidney, lung, bone, bone marrow, brain, and endothelium. ${ }^{29}$ Use of estriol in antiaging medicine is based on the fact that it is a weak estrogen and potentially safer in terms of breast cancer. Theoretically, lower estrogenic activity on tissue such as the breast and the endometrium should be related to lower cancer risk. Nevertheless, affinity of receptors does not completely correspond to estrogenic activity at a tissue level. ${ }^{29}$ Despite it being considered a weak estrogen, oral (but not vaginal) estriol has a proliferative effect on endometrial tissue, exposing women to a higher risk for endometrial cancer. ${ }^{30}$ Moreover, studies on the effect of estriol on breast tissue in humans have been inconsistent. Thus, estriol administration (regardless of the route) has been related to higher risks for lobular but not tubular or ductal breast cancer. ${ }^{31}$ Others found no relationship between short- and long-term use of estriol (over 5 years) and breast cancer incidence. ${ }^{27}$

It would be rather premature to state that estriol is a safe alternative to classic HRT, and further studies are necessary. Regarding its efficiency, positive effects of estriol on vaginal, urinary, and climacteric symptoms have been reported in several studies. ${ }^{32-36} \mathrm{~A}$ slight increase in BMD was reported in an open-label study ${ }^{34}$ but has not been confirmed by others. ${ }^{33,36}$

\section{Progesterone}

In order to counter estrogen's proliferative effect on the endometrium, nonhysterectomized women should also be administered progesterone. Antiaging specialists put forward the benefits of bioidentical progesterone treatment compared with synthetic progestins regarding efficiency and safety. Indeed, synthetic progestins may have different affinities for hormone receptors (androgen, progesterone, glucocorticoid, mineralocorticoid, estrogen, and growth hormone $[\mathrm{GH}]$ ) and thus different effects on target tissue that are difficult to 
foresee and control. ${ }^{37-39}$ Bioidentical progesterone produced from yams or soybeans is available worldwide. It is usually micronized in order to increase oral bioavailability. ${ }^{6} \mathrm{~A}$ total of $200 \mathrm{mg}$ daily for 12 days per month efficiently inhibits estrogen's effect on the endometrium. ${ }^{6}$

Oral bioidentical progesterone, when combined with estradiol, improves sleep quality more efficiently than synthetic medroxyprogesterone acetate. ${ }^{7}$ Moreover, a positive effect of bioidentical progesterone on the bone (inhibition of the decrease in trabecular number, enhancement of mineral apposition, and bone formation) has been shown in animal studies. ${ }^{40}$ Additionally, cardiovascular safety profile seems better with bioidentical progesterone compared with synthetic progestins. ${ }^{19,37}$ Indeed, a more positive effect of bioidentical progesterone compared with synthetic progestins on blood pressure, through an antimineralocorticoid effect, has been put forward. ${ }^{19,37}$ Also, bioidentical progesterone blunts to a lesser degree the positive effects of estrogens on HDL, compared with synthetic progestins. ${ }^{41}$ Moreover, contrarily to synthetic progestins, when combined with transdermal estradiol, bioidentical progesterone does not increase the risk for venous thromboembolic events. ${ }^{20}$ Finally, a lower risk for breast cancer has been reported with bioidentical progesterone compared with synthetic progestins. ${ }^{28,42}$ In general, oral bioidentical progesterone seems to be more efficient and safer than synthetic progestins.

On the other hand, data on potential benefits of transdermal bioidentical progesterone remain inconsistent. ${ }^{6}$ Some report that bypassing the "first-pass" liver effect, which is responsible for metabolizing approximately 90\% of progesterone ingested, may actually help avoid side effects due to metabolites, such as drowsiness. ${ }^{37}$ Nevertheless, the efficiency of transdermal and vaginal routes remains a matter of discussion, some reporting identical and more stable progesterone levels with these formulations and others an insufficient effect for treating menopause-related symptoms but also for preventing endometrial proliferation and hyperplasia. ${ }^{37,43,44}$ Such forms need to be validated in largescale studies regarding their efficiency and safety before they may be proposed as standard treatment.

Antiaging specialists promote the use of bioidentical hormones as a more natural way to supplement hormone deficiencies in postmenopausal women. In theory, it is very attractive to be able to supplement with a hormone compound that is identical to the one lacking. Indeed, hormones participate in most of the body's functions in different degrees, and hormone analogs may only partially fulfil the multiple roles of the natural hormone. Preliminary studies seem to support a better safety profile of bioidentical hormones, but this should be confirmed by large-scale studies. Also, further studies are necessary that directly compare synthetic hormones with bioidentical hormones, in terms of efficiency and safety.

\section{Testosterone}

Testosterone $(\mathrm{T})$ is the major circulating hormone in men, but it is also present, to a lower degree, in women. It is produced by Leydig cells in men, whereas in postmenopausal women its production is mostly dependent on transformation from dehydroepiandrosterone (DHEA) through intracrine mechanisms. ${ }^{45,46}$ In men, $44 \%$ of circulating $\mathrm{T}$ is bound to a transport protein, the sex hormone-binding globulin (SHBG). Another 50\% is bound to albumin, 4\% to cortisol-binding globulin, and $2 \%$ remains free. Active or bioavailable $\mathrm{T}$ includes free and albumin-bound $\mathrm{T}$ (as albumin's affinity for $\mathrm{T}$ is 1,000 times lower compared with SHBG). ${ }^{47-49}$

Total $\mathrm{T}$ decreases with age at a rate of $0.4 \%-1 \%$ per year. ${ }^{50-52}$ This results in a $20 \%$ and $30 \%-50 \%$ prevalence of low total $\mathrm{T}$ levels in men aged $>60$ years and $>80$ years, respectively. ${ }^{5,53}$ Andropause or late onset male hypogonadism diagnosis requires both the presence of symptoms and low $\mathrm{T}$ plasma levels. ${ }^{5}$ The prevalence of andropause is increasing with age, reaching $5 \%$ in patients aged between 70 years and 79 years. $^{5}$

\section{Effects of testosterone decline on the aging process and age-related diseases}

Low $\mathrm{T}$ has been related to various age-associated conditions. ${ }^{5}$ Low muscle mass ${ }^{54,55}$ and strength, ${ }^{54}$ as well as worse functional status, ${ }^{56}$ are more frequent in elderly men with low $\mathrm{T}$ plasma levels. Moreover, low $\mathrm{T}$, together with alcohol and glucocorticoids, is one of the most frequent causes of osteoporosis in older men. ${ }^{57}$ Studies have also suggested a relationship between low $\mathrm{T}$ levels, mild cognitive impairment, and Alzheimer's disease. ${ }^{58,59}$

\section{Efficiency and safety of testosterone supplementation}

$\mathrm{T}$ supplementation has been studied in aging populations regarding age-related conditions. Thus, T replacement therapy is beneficial for sarcopenia ${ }^{55,56,60}$ and bone density in older men. ${ }^{61,62}$ Concerning cognitive function, T supplementation has positive effects on verbal, spatial ${ }^{63-65}$ and working memory, ${ }^{66}$ visuospatial function, ${ }^{67-69}$ and executive function. ${ }^{70}$

Contrary to the widespread belief that $\mathrm{T}$ is related to a higher cardiovascular risk, studies show that atherosclerosis 
is mostly related to low T levels. ${ }^{71-77}$ Moreover, direct antianginal effects have been described with $\mathrm{T}$ administration. ${ }^{78,79}$ Nevertheless, an increase of adverse cardiovascular effects with $\mathrm{T}$ administration has also been described. Treatment should not be initiated in patients with recent ischemic heart disease or heart failure. ${ }^{80,81}$

One of the main concerns with $\mathrm{T}$ supplementation is polycythemia. Indeed, an increase of hematocrit following $\mathrm{T}$ treatment is fairly frequent, mostly with intramuscular formulations and in older populations. ${ }^{82,83}$ For this reason, a follow-up of hematocrit levels every 6 months for 18 months and yearly thereafter should always be planned when $\mathrm{T}$ treatment is introduced. If hematocrit exceeds $52 \%-55 \%$, treatment should be decreased or discontinued. ${ }^{5}$

Ever since animal studies reported prostate cancer growth stimulation by $\mathrm{T}$ administration,${ }^{84}$ concerns have been put forward about the role of $\mathrm{T}$ in promoting or accelerating the development of prostate cancer in humans. Nevertheless, most recent studies have failed to confirm a relationship between $\mathrm{T}$ levels and the risk for prostate cancer. ${ }^{85-87} \mathrm{On}$ the contrary, increased risk for prostate cancer onset, higher 5 -year biochemical relapse rates, and higher Gleason scores were associated with low T plasma levels. ${ }^{85,88}$ Concordantly, the $\mathrm{T}$ supplementation safety profile is rather satisfying regarding prostate cancer risk, ${ }^{82,83,89-92}$ even for patients after treatment for prostate cancer by radical prostatectomy, ${ }^{89}$ brachytherapy, ${ }^{93}$ or external beam radiation. ${ }^{94}$ Of course, active prostate cancer formally prohibits $T$ treatment. Finally, follow-up of low urinary tract symptoms and prostate-specific antigen (PSA) levels is mandatory. ${ }^{82,92}$

$\mathrm{T}$ administration for andropause treatment should follow very strict rules concerning the choice of the patient to treat, as well as the follow-up of different parameters such as PSA and hematocrit. ${ }^{5}$ When a male presents with symptoms of hypogonadism, a total $\mathrm{T}$ measure should be taken. Free $\mathrm{T}$ should be measured either when total $\mathrm{T}$ levels are close to the lower limit of normal values or in situations where SHBG alterations may be suspected (treatment with progestins, estrogens, anticonvulsivants, or glucocorticoids, as well as conditions such as HIV infection, thyroid disorders, acromegaly, nephritic syndrome, diabetes mellitus, and liver cirrhosis). Pretreatment control should include a detailed history for congestive heart failure, coronary disease, sleep apnea, low urinary tract symptoms, and prostate carcinoma. A digital prostate examination should be carried out and PSA blood levels should be checked. In case of an abnormal clinical examination or PSA levels $>4 \mathrm{ng} / \mathrm{mL}$ (or PSA $>3 \mathrm{ng} / \mathrm{mL}$ in men at high risk), a transrectal ultrasound-guided prostate biopsy should be performed. T supplementation should not be started in cases of suspected prostate cancer, severe symptoms of low urinary tract (International Prostate Symptom Score $>19$ ), hematocrit $>50 \%$, poorly controlled congestive heart failure, ischemic heart disease in the preceding 6 months, or untreated sleep apnea. In general, studies concur that if $\mathrm{T}$ is used according to international guidelines and plasma levels do not reach supraphysiologic levels, serious adverse effects are rare. ${ }^{95}$

\section{Future perspectives of testosterone supplementation}

Label use of T supplementation in the US as well as in most European countries concerns only male hypogonadism. Unfortunately, it is also widely used as an anabolic steroid for its effects on muscle mass. On the other hand, $\mathrm{T}$ is also underused. Partly because of widespread concerns about $\mathrm{T}$ treatment safety, only $5 \%$ of men in the US with hypogonadism receive appropriate treatment. ${ }^{91}$ It is therefore vital that physicians treating patients at high risk for male hypogonadism, such as elderly patients, are well aware of the benefits, risks, and treatment modalities of $\mathrm{T}$ supplementation. Indeed, its positive effects on bone and muscle could make $\mathrm{T}$ extremely interesting in geriatric rehabilitation protocols. Its role in cognitive and mood disorder treatment is yet to be defined. Finally, studies are progressively appearing concerning its use in chronic diseases related to sarcopenia and cachexia, such as chronic obstructive pulmonary disease. ${ }^{96}$

\section{Dehydroepiandrosterone}

DHEA is a steroid prohormone produced by the adrenal glands and transformed in target tissue through intracrine mechanisms to androgens or estrogens. Plasma DHEA levels decline with age. By the age of 70-80 years, levels may be as low as $10 \%-20 \%$ of those encountered in young individuals. ${ }^{46}$

The importance of DHEA in steroid hormone production increases with age. ${ }^{4}$ Indeed, in postmenopausal women, production of estrogens by the ovaries declines dramatically, making the adrenals the only source of steroid hormones through DHEA..$^{97,98}$ In men, although T secretion by the testicles continues late into life, $\mathrm{T}$ levels progressively decline, and DHEA's importance in steroid hormone production is also higher with increasing age. DHEA's effect is mostly through its hormone end products. Nevertheless, in vitro studies have shown that DHEA may directly increase nitric oxide production from intact endothelial cells, probably through $\mathrm{G}$ protein-dependent activation of endothelial nitric oxide 
synthetase, thus supporting proper intrinsic physiological functions. ${ }^{99}$

\section{Effects of DHEA decline on the aging process and age-related diseases}

DHEA decline with age is clinically relevant and has been related to a variety of age-related conditions. ${ }^{4} \mathrm{~A}$ positive relationship between DHEA levels and muscle mass, muscle strength, as well as mobility and a lower risk for falls, has been described in elderly individuals. ${ }^{100-103}$ Moreover, a positive effect of DHEA on BMD through transformation to estrogens (in vitro human osteoblasts present an aromatase activity), ${ }^{104}$ but also directly through mitogen-activated protein kinase signaling pathways, has been suggested. ${ }^{105}$ Indeed, DHEA levels have been positively related to BMD in women ${ }^{104}$ and men. ${ }^{106}$

Concerning neuropsychiatric diseases, the relationship between DHEA and cognitive disorders has not been studied sufficiently in order to formally conclude on its effect on dementia onset and progression. ${ }^{4}$ On the other hand, the relationship between DHEA levels and mood disorders seems clearer. Low levels of DHEA have been related to depression symptoms. ${ }^{107,108}$

The relationship between DHEA levels and cardiovascular disease risk factors such as cholesterol and glucose tolerance is inconsistent. ${ }^{4}$ Nevertheless, studies have shown that low DHEA levels are related to a higher risk for atherosclerosis, ${ }^{109-12}$ heart failure, ${ }^{113,114}$ cardiovascular complications, and overall mortality. ${ }^{115,116}$

DHEA seems to play a rather important role in sexual function for both sexes. Low levels of DHEA were related to a higher risk for erectile dysfunction in men $^{117-119}$ and low sexual responsiveness in women. ${ }^{45,120}$

\section{Efficiency and safety of DHEA supplementation}

DHEA administration has had positive effects on muscle mass and strength, as well as physical performance parameters. ${ }^{121-125}$ Also, DHEA has had positive effects on BMD both in women ${ }^{122,126-130}$ and in men. ${ }^{122,128,129,131,132}$ Furthermore, DHEA supplementation has shown positive effects on mood ${ }^{133-137}$ as well as sexual function both for $\operatorname{men}^{133,138}$ and for women. ${ }^{139-143}$ However, no positive effects on erectile function were found when conditions such as diabetes or neurological disorders were present. ${ }^{144}$ Finally, DHEA supplementation has improved menopause symptoms in perimenopausal and early postmenopausal women. ${ }^{140,145,146}$ Also, intravaginal formulations have had a positive effect in reversing vaginal mucosa atrophy in postmenopausal women. ${ }^{146}$

Most studies show a very satisfying safety profile for DHEA supplementation. Only minimal effects such as mild acne, seborrhea, facial hair growth, and ankle swelling have been reported in women. ${ }^{147,148}$ Otherwise, DHEA supplementation has had a rather positive effect on skin. ${ }^{139}$ No significant effect has been reported on hormone-dependent tumors such as breast and prostate cancer. ${ }^{97,132}$ On the contrary, animal studies showed that DHEA inhibits tumors of lymphatic tissue, lung, colon, breast, liver, and skin. ${ }^{149,150}$ Nevertheless, to our knowledge, the longest study durations for DHEA supplementation did not exceed 2 years. Consequently, no data exist on treatment safety regarding hormone-dependent tumors (breast, prostate, and endometrium), cardiovascular risk, or mortality for longer treatments.

\section{Future perspectives of DHEA supplementation}

DHEA has the status of a dietary supplement and is sold over the counter in the US. In Europe, in most countries it is either forbidden (France) or subject to medical prescription (Switzerland). DHEA is widely used in antiaging medicine and is considered as a "fountain of youth" hormone by some. As it is a prohormone, it is also used as a "hormone regulator", permitting the body to reach a hormone equilibrium. DHEA is indeed a prohormone with positive effects on several age-related diseases. Supplementing a prohormone is also extremely interesting, as it would theoretically provide the organism with the possibility to use it and transform it according to local and general hormone needs. For the future, the role of DHEA supplementation in specific indications such as sarcopenia, falls and rehabilitation protocols, osteoporosis, mood and cognitive disorders, and also sexual wellbeing needs to be better studied in longer and larger studies. Finally, physicians prescribing DHEA should consider and inform their patients of the fact that long-term effects concerning efficiency, but also safety, are still uncertain.

\section{Growth hormone}

GH is widely used in antiaging medicine in order to reverse the effects of aging. GH levels decrease with age. ${ }^{151}$ This decrease may be so important that insulin growth factor-1 (IGF-1) levels found in elderly individuals are as low as those encountered in adult patients with established GH deficiency. ${ }^{152,153}$ Multiple factors may influence GH decrease, but it seems mostly related to a decrease in GH-releasing hormone secretion together with higher somatostatin 
secretion levels. GH decrease combined with the fact that frailty and aging share several characteristics with $\mathrm{GH}$ deficiency encountered in younger adults (increase of fat mass and decrease of lean mass, cognitive impairment, psychological difficulties, dry and thin skin, and impaired cardiac capacity $)^{154}$ have made it rather popular in antiaging medicine.

\section{Effects of $\mathrm{GH}$ decline on the aging process and age-related diseases}

The effect of GH on longevity and whether GH is a proaging or antiaging hormone is a matter of controversy. Animal studies in which interventions reduced GH and IGF-1 levels or increased resistance to GH resulted in an increased life span. ${ }^{155,156}$ Concordantly, age-related cognitive alterations and decreased life span were encountered in animal models producing supraphysiological levels of GH. Potential underlying mechanisms of low GH effects include reduced oxidative metabolism and lower oxidative stress, increased stress resistance, and enhanced sensitivity to insulin. ${ }^{157}$ In humans, recent studies on Ecuadorian individuals who carry mutations in the $\mathrm{GH}$ receptor gene, leading to severe GH receptor and IGF-1 deficiencies, showed a decreased incidence of malignancies as well as diabetes, compared with control subjects. Higher insulin sensitivity in this population as well as higher antioxidant capacities were reported. ${ }^{158}$ Others reported associations between GH deficiency or GH resistance and increased longevity, better lipid profiles, less atherosclerosis and vascular pathology, as well as a decreased risk for developing cancer. ${ }^{159-162}$

As a matter of fact, both too high and too low levels of GH and IGF-1 seem to be associated with reduced longevity in humans. ${ }^{152}$ Thus, others reported reduced longevity ${ }^{163}$ as well as higher cardiovascular risk and higher cardiovascular and cerebrovascular mortality in GH-deficient patients. ${ }^{164,165}$ Concerning osteoporosis, low IGF-1 levels have been related to lower BMD in men. ${ }^{166,167} \mathrm{GH}$ and IGF-1 receptors are present in multiple areas of the human brain (hippocampus, superficial and deep cortical layers, olfactory bulb, thalamus, and amygdala). ${ }^{168-170}$ In humans, one longitudinal study found a correlation between low total but not free IGF-1 levels and incident decline in Mini Mental State Examination scores after an average 1.9-year follow-up in a group of 186 individuals aged between 55 years and 80 years. ${ }^{170}$ Another study showed a positive correlation between IGF-1 levels and Mini Mental State Examination scores in a group of 22 individuals aged between 65 years and 86 years. ${ }^{171}$ Unfortunately, very few studies have explored the effects of GH on cognition, and most of them are small and rather short. To our knowledge, none has studied the relationship between somatotropic status and the risk for dementia in elderly populations.

\section{Efficiency and safety of GH supplementation}

The effect of GH supplementation on age-related diseases has been studied. Potential positive effects of GH treatment concern body composition, with an increase in lean mass and a decrease in fat tissue. ${ }^{172,173}$ Nevertheless, this increase in muscle mass was not always related to an improved physical ability. ${ }^{172,174}$ The possibility that higher measures of lean mass may be related to increased fluid retention has been put forward. ${ }^{152,175}$ Studies on the effects of GH supplementation on BMD ${ }^{152,176}$ as well as on lipid profile and glucose metabolism have been rather inconsistent. ${ }^{176}$

Concerning cognitive disorders, animal studies showed that restoring IGF-1 levels in transgenic mice with Alzheimer's disease decreased $\alpha \beta$-amyloid accumulation, a hallmark neuropathological lesion of Alzheimer's disease. ${ }^{177}$ In humans, treatment with GH-releasing hormone analogs improved cognition in healthy elderly individuals but also in patients with mild cognitive impairment. ${ }^{177,178}$ Also, a 1-year GH supplementation had positive effects on cognitive performance of elderly patients with GH deficiency. ${ }^{179}$ Further studies are necessary in order to formally conclude on the potential effect of $\mathrm{GH}$ supplementation on cognitive function and, more specifically, on dementia risk.

The safety of GH supplementation in aging individuals is still a matter of debate. No increase in the risk for cancer with GH supplementation has been reported in young patients with overt deficiency. ${ }^{180}$ In older patients with agerelated GH deficiency, short-term clinical trials observed no increase of cancer incidence or deaths, ${ }^{152}$ but no data exist for long-term treatments. Moreover, studies in healthy elderly have shown a higher risk for adverse effects of GH supplementation, such as carpal tunnel syndrome, gynecomastia, and fluid retention. Concerns have also been put forward about a dose-dependent increase of insulin resistance with GH treatment. ${ }^{176}$

\section{Future perspectives of $\mathrm{GH}$ supplementation}

Despite clear positive effects in GH-deficient patients, GH supplementation in antiaging medicine for healthy elderly 
individuals with low GH levels due to age is still a matter of debate, with unclear pros and cons. ${ }^{181}$ Further studies are required regarding specific indications and the long-term safety and efficiency of such treatments.

\section{Conclusion}

Hormone level decline is a part of aging. It is not yet clear whether this decline should be considered as a physiologic reaction of the body to aging and thus a part of "normal" or "healthy" aging or whether actively treating it would actually help to prevent and treat serious or even life-threatening agerelated conditions. We strongly believe that hormones should be a part of geriatric care. Nevertheless, "countering aging effects" is too general as an indication, is subject to confusion, and cannot be a basis for treatment. Large-scale studies are necessary in order to better define precise indications and treatment modalities in aging and elderly individuals. In-depth assessments of hormone needs and precise follow-up plans should be elaborated for everyday clinical practice. Finally, once hormone supplementation is installed, treatment may last for years or decades. Long-term or very long-term safety of such treatments should also be a matter of study.

\section{Disclosure}

The authors report no conflicts of interest in this report.

\section{References}

1. Binstock RH. Anti-aging medicine and research: a realm of conflict and profound societal implications. J Gerontol A Biol Sci Med Sci. 2004;59:B523-B533.

2. Stuckelberger A. Anti-ageing Medicine. Myths and Chances. 1st ed. Zürich, Switzerland: Hochschulverlag; 2008.

3. Zouboulis CC, Makrantonaki E. Hormonal therapy of intrinsic aging. Rejuvenation Res. 2012;15:302-312.

4. Samaras N, Samaras D, Frangos E, Forster A, Philippe J. A review of age-related dehydroepiandrosterone decline and its association with well-known geriatric syndromes: is treatment beneficial? Rejuvenation Res. 2013;16(4):285-294.

5. Samaras N, Samaras D, Lang PO, et al. A view of geriatrics through hormones. What is the relation between andropause and well-known geriatric syndromes? Maturitas. 2013;74(3):213-219.

6. Sites CK. Bioidentical hormones for menopausal therapy. Womens Health (Lond Engl). 2008;4:163-171.

7. Montplaisir J, Lorrain J, Denesle R, Petit D. Sleep in menopause: differential effects of two forms of hormone replacement therapy. Menopause. 2001;8:10-16.

8. Cirigliano M. Bioidentical hormone therapy: a review of the evidence. $J$ Womens Health (Larchmt). 2007;16:600-631.

9. MacLennan A, Lester S, Moore V. Oral oestrogen replacement therapy versus placebo for hot flushes. Cochrane Database Syst Rev. 2001;(1):CD002978.

10. Cauley JA, Robbins J, Chen Z, et al. Effects of estrogen plus progestin on risk of fracture and bone mineral density: the Women's Health Initiative randomized trial. JAMA. 2003;290:1729-1738.

11. Rymer J, Morris EP. Extracts from "Clinical Evidence": menopausal symptoms. BMJ. 2000;321:1516-1519.
12. Rossouw JE, Anderson GL, Prentice RL, et al. Risks and benefits of estrogen plus progestin in healthy postmenopausal women: principal results from the Women's Health Initiative randomized controlled trial. JAMA. 2002;288:321-333.

13. Hersh AL, Stefanick ML, Stafford RS. National use of postmenopausal hormone therapy: annual trends and response to recent evidence. JAMA. 2004;291:47-53.

14. Estrogen and progestogen use in peri- and postmenopausal women: March 2007 position statement of The North American Menopause Society. Menopause. 2007;14:168-182.

15. Ettinger B, Ensrud KE, Wallace R, et al. Effects of ultralow-dose transdermal estradiol on bone mineral density: a randomized clinical trial. Obstet Gynecol. 2004;104:443-451.

16. Kaufert P, Boggs PP, Ettinger B, Woods NF, Utian WH. Women and menopause: beliefs, attitudes, and behaviors. The North American Menopause Society. 1997 Menopause Survey. Menopause. 1998;5:197-202.

17. Files JA, Ko MG, Pruthi S. Bioidentical hormone therapy. Mayo Clin Proc. 2011;86:673-680.

18. Coelingh Bennink HJ. Are all estrogens the same? Maturitas. 2004;47: 269-275.

19. L'Hermite M, Simoncini T, Fuller S, Genazzani AR. Could transdermal estradiol + progesterone be a safer postmenopausal HRT? A review. Maturitas. 2008;60:185-201.

20. Canonico M, Oger E, Plu-Bureau G, et al. Hormone therapy and venous thromboembolism among postmenopausal women: impact of the route of estrogen administration and progestogens: the ESTHER study. Circulation. 2007;115:840-845.

21. SchunkertH, Danser AH, Hense HW, Derkx FH, Kurzinger S, Riegger GA. Effects of estrogen replacement therapy on the renin-angiotensin system in postmenopausal women. Circulation. 1997;95:39-45.

22. Blumel JE, Castelo-Branco C, Leal T, et al. Effects of transdermal estrogens on endothelial function in postmenopausal women with coronary disease. Climacteric. 2003;6:38-44.

23. Le Gal G, Gourlet V, Hogrel P, Plu-Bureau G, Touboul PJ, Scarabin PY. Hormone replacement therapy use is associated with a lower occurrence of carotid atherosclerotic plaques but not with intima-media thickness progression among postmenopausal women. The vascular aging (EVA) study. Atherosclerosis. 2003;166:163-170.

24. Opatrny L, Dell'Aniello S, Assouline S, Suissa S. Hormone replacement therapy use and variations in the risk of breast cancer. BJOG. 2008;115:169-175; discussion 75.

25. Lippert C, Seeger H, Mueck AO. The effect of endogenous estradiol metabolites on the proliferation of human breast cancer cells. Life Sci. $2003 ; 72: 877-883$.

26. Mueck AO, Seeger H. Breast cancer: are estrogen metabolites carcinogenic? Climacteric. 2007;10 Suppl. 2:62-65.

27. Lyytinen H, Pukkala E, Ylikorkala O. Breast cancer risk in postmenopausal women using estrogen-only therapy. Obstet Gynecol. 2006;108: 1354-1360.

28. Fournier A, Berrino F, Clavel-Chapelon F. Unequal risks for breast cancer associated with different hormone replacement therapies: results from the E3N cohort study. Breast Cancer Res Treat. 2008;107: $103-111$.

29. Kuiper GG, Carlsson B, Grandien K, et al. Comparison of the ligand binding specificity and transcript tissue distribution of estrogen receptors alpha and beta. Endocrinology. 1997;138:863-870.

30. Weiderpass E, Baron JA, Adami HO, et al. Low-potency oestrogen and risk of endometrial cancer: a case-control study. Lancet. 1999;353:1824-1828.

31. Rosenberg LU, Magnusson C, Lindstrom E, Wedren S, Hall P, Dickman PW. Menopausal hormone therapy and other breast cancer risk factors in relation to the risk of different histological subtypes of breast cancer: a case-control study. Breast Cancer Res. 2006;8:R11.

32. Iosif CS. Effects of protracted administration of estriol on the lower genito urinary tract in postmenopausal women. Arch Gynecol Obstet. 1992;251:115-120. 
33. Takahashi K, Manabe A, Okada M, Kurioka H, Kanasaki H, Miyazaki K. Efficacy and safety of oral estriol for managing postmenopausal symptoms. Maturitas. 2000;34:169-177.

34. Minaguchi H, Uemura T, Shirasu K, et al. Effect of estriol on bone loss in postmenopausal Japanese women: a multicenter prospective open study. J Obstet Gynaecol Res. 1996;22:259-265.

35. Raz R, Stamm WE. A controlled trial of intravaginal estriol in postmenopausal women with recurrent urinary tract infections. $N$ Engl $J$ Med. 1993;329:753-756.

36. Yang TS, Tsan SH, Chang SP, Ng HT. Efficacy and safety of estriol replacement therapy for climacteric women. Zhonghua Yi Xue Za Zhi (Taipei). 1995;55:386-391.

37. Moskowitz D. A comprehensive review of the safety and efficacy of bioidentical hormones for the management of menopause and related health risks. Altern Med Rev. 2006;11:208-223.

38. Sitruk-Ware R. Pharmacological profile of progestins. Maturitas. 2004;47:277-283.

39. Sitruk-Ware R. Progestogens in hormonal replacement therapy: new molecules, risks, and benefits. Menopause. 2002;9:6-15.

40. Schmidt IU, Wakley GK, Turner RT. Effects of estrogen and progesterone on tibia histomorphometry in growing rats. Calcif Tissue Int. 2000;67:47-52.

41. The Writing Group for the PEPI Trial. Effects of estrogen or estrogen/ progestin regimens on heart disease risk factors in postmenopausa women. The Postmenopausal Estrogen/Progestin Interventions (PEPI) Trial. JAMA. 1995;273:199-208.

42. Fournier A, Berrino F, Riboli E, Avenel V, Clavel-Chapelon F. Breast cancer risk in relation to different types of hormone replacement therapy in the E3N-EPIC cohort. Int J Cancer. 2005;114:448-454.

43. Wren BG, Champion SM, Willetts K, Manga RZ, Eden JA. Transdermal progesterone and its effect on vasomotor symptoms, blood lipid levels, bone metabolic markers, moods, and quality of life for postmenopausal women. Menopause. 2003;10:13-18.

44. Wren BG, McFarland K, Edwards L, et al. Effect of sequential transdermal progesterone cream on endometrium, bleeding pattern, and plasma progesterone and salivary progesterone levels in postmenopausal women. Climacteric. 2000;3:155-160.

45. Panjari M, Davis SR. DHEA therapy for women: effect on sexual function and wellbeing. Hum Reprod Update. 2007;13: 239-248.

46. Genazzani AD, Lanzoni C, Genazzani AR. Might DHEA be considered a beneficial replacement therapy in the elderly? Drugs Aging. 2007:24:173-185.

47. Hyde Z, Flicker L, Almeida OP, et al. Low free testosterone predicts frailty in older men: the health in men study. J Clin Endocrinol Metab. 2010;95:3165-3172.

48. Dunn JF, Nisula BC, Rodbard D. Transport of steroid hormones: binding of 21 endogenous steroids to both testosterone-binding globulin and corticosteroid-binding globulin in human plasma. J Clin Endocrinol Metab. 1981;53:58-68.

49. Pardridge WM. Serum bioavailability of sex steroid hormones. Clin Endocrinol Metab. 1986;15:259-278.

50. Leifke E, Gorenoi V, Wichers C, Von Zur Muhlen A, Von Buren E, Brabant G. Age-related changes of serum sex hormones, insulin-like growth factor-1 and sex-hormone binding globulin levels in men: cross-sectional data from a healthy male cohort. Clin Endocrinol (Oxf). 2000;53:689-695.

51. Morley JE, Kim MJ, Haren MT. Frailty and hormones. Rev Endocr Metab Disord. 2005;6:101-108.

52. Wu FC, Tajar A, Pye SR, et al. Hypothalamic-pituitary-testicular axis disruptions in older men are differentially linked to age and modifiable risk factors: the European Male Aging Study. J Clin Endocrinol Metab. 2008;93:2737-2745.

53. Lapauw B, Goemaere S, Zmierczak H, et al. The decline of serum testosterone levels in community-dwelling men over 70 years of age: descriptive data and predictors of longitudinal changes. Eur J Endocrinol. 2008; 159:459-468.
54. Sattler FR, Castaneda-Sceppa C, Binder EF, et al. Testosterone and growth hormone improve body composition and muscle performance in older men. J Clin Endocrinol Metab. 2009;94: 1991-2001.

55. Storer TW, Woodhouse L, Magliano L, et al. Changes in muscle mass, muscle strength, and power but not physical function are related to testosterone dose in healthy older men. J Am Geriatr Soc. 2008;56: 1991-1999.

56. Hyde Z, Norman PE, Flicker L, et al. Low free testosterone predicts mortality from cardiovascular disease but not other causes: the Health in Men Study. J Clin Endocrinol Metab. 2008;97:179-189.

57. Bain J. Andropause. Testosterone replacement therapy for aging men. Can Fam Physician. 2001;47:91-97.

58. Emmelot-Vonk MH, Verhaar HJ, Nakhai Pour HR, et al. Effect of testosterone supplementation on functional mobility, cognition, and other parameters in older men: a randomized controlled trial. JAMA. 2008;299:39-52.

59. Chu LW, Tam S, Lee PW, et al. Bioavailable testosterone is associated with a reduced risk of amnestic mild cognitive impairment in older men. Clin Endocrinol (Oxf). 2008;68:589-598.

60. Srinivas-Shankar U, Roberts SA, Connolly MJ, et al. Effects of testosterone on muscle strength, physical function, body composition, and quality of life in intermediate-frail and frail elderly men: a randomized, double-blind, placebo-controlled study. J Clin Endocrinol Metab. 2010;95:639-650.

61. Kenny AM, Kleppinger A, Annis K, et al. Effects of transdermal testosterone on bone and muscle in older men with low bioavailable testosterone levels, low bone mass, and physical frailty. J Am Geriatr Soc. 2010;58:1134-1143.

62. Snyder PJ, Peachey H, Hannoush P, et al. Effect of testosterone treatment on bone mineral density in men over 65 years of age. $J$ Clin Endocrinol Metab. 1999;84:1966-1972.

63. Cherrier MM, Asthana S, Plymate S, et al. Testosterone supplementation improves spatial and verbal memory in healthy older men. Neurology. 2001;57:80-88.

64. Cherrier MM, Matsumoto AM, Amory JK, et al. Testosterone improves spatial memory in men with Alzheimer disease and mild cognitive impairment. Neurology. 2005;64:2063-2068.

65. Cherrier MM, Matsumoto AM, Amory JK, et al. Characterization of verbal and spatial memory changes from moderate to supraphysiological increases in serum testosterone in healthy older men. Psychoneuroendocrinology. 2007;32:72-79.

66. Janowsky JS, Chavez B, Orwoll E. Sex steroids modify working memory. J Cogn Neurosci. 2000;12:407-414.

67. Janowsky JS, Oviatt SK, Orwoll ES. Testosterone influences spatial cognition in older men. Behav Neurosci. 1994;108:325-332.

68. Lu PH, Masterman DA, Mulnard R, et al. Effects of testosterone on cognition and mood in male patients with mild Alzheimer disease and healthy elderly men. Arch Neurol. 2006;63:177-185.

69. Tan RS, Pu SJ. A pilot study on the effects of testosterone in hypogonadal aging male patients with Alzheimer's disease. Aging Male. 2003; 6:13-17.

70. Kenny AM, Bellantonio S, Gruman CA, Acosta RD, Prestwood KM. Effects of transdermal testosterone on cognitive function and health perception in older men with low bioavailable testosterone levels. $J$ Gerontol A Biol Sci Med Sci. 2002;57:M321-M325.

71. Hyde Z, Norman PE, Flicker L, et al. Elevated LH predicts ischaemic heart disease events in older men: the Health in Men Study. Eur J Endocrinol. 2011;164:569-577.

72. Yeap BB, Hyde Z, Norman PE, Chubb SA, Golledge J. Associations of total testosterone, sex hormone-binding globulin, calculated free testosterone, and luteinizing hormone with prevalence of abdominal aortic aneurysm in older men. $J$ Clin Endocrinol Metab. 2010;95: $1123-1130$.

73. Rosano GM, Sheiban I, Massaro R, et al. Low testosterone levels are associated with coronary artery disease in male patients with angina. Int J Impot Res. 2007;19:176-182. 
74. English KM, Mandour O, Steeds RP, Diver MJ, Jones TH, Channer KS. Men with coronary artery disease have lower levels of androgens than men with normal coronary angiograms. Eur Heart J. 2000;21:890-894.

75. Yeap BB, Hyde Z, Almeida OP, et al. Lower testosterone levels predict incident stroke and transient ischemic attack in older men. J Clin Endocrinol Metab. 2009;94:2353-2359.

76. Ohlsson C, Barrett-Connor E, Bhasin S, et al. High serum testosterone is associated with reduced risk of cardiovascular events in elderly men. The MrOS (Osteoporotic Fractures in Men) Study in Sweden. J Am Coll Cardiol. 2011;58:1674-1681.

77. Liu PY, Death AK, Handelsman DJ. Androgens and cardiovascular disease. Endocr Rev. 2003;24:313-340.

78. Rosano GM, Leonardo F, Pagnotta P, et al. Acute anti-ischemic effect of testosterone in men with coronary artery disease. Circulation. 1999;99:1666-1670.

79. English KM, Steeds RP, Jones TH, Diver MJ, Channer KS. Low-dose transdermal testosterone therapy improves angina threshold in men with chronic stable angina: a randomized, double-blind, placebocontrolled study. Circulation. 2000;102:1906-1911.

80. Basaria S, Coviello AD, Travison TG, et al. Adverse events associated with testosterone administration. N Engl J Med. 2010;363:109-122.

81. Vigen R, O’Donnell CI, Baron AE, et al. Association of testosterone therapy with mortality, myocardial infarction, and stroke in men with low testosterone levels. JAMA. 2013;310:1829-1836.

82. Wald M, Meacham RB, Ross LS, Niederberger CS. Testosterone replacement therapy for older men. J Androl. 2006;27:126-132.

83. Bhasin S, Basaria S. Diagnosis and treatment of hypogonadism in men. Best Pract Res Clin Endocrinol Metab. 2011;25:251-270.

84. Noble RL. The development of prostatic adenocarcinoma in $\mathrm{Nb}$ rats following prolonged sex hormone administration. Cancer Res. 1977;37:1929-1933.

85. Pierorazio PM, Ferrucci L, Kettermann A, Longo DL, Metter EJ, Carter HB. Serum testosterone is associated with aggressive prostate cancer in older men: results from the Baltimore Longitudinal Study of Aging. BJU Int. 2010;105:824-829.

86. Travis RC, Key TJ, Allen NE, et al. Serum androgens and prostate cancer among 643 cases and 643 controls in the European Prospective Investigation into Cancer and Nutrition. Int $J$ Cancer. 2007;121:1331-1338.

87. Roddam AW, Allen NE, Appleby P, Key TJ. Endogenous sex hormones and prostate cancer: a collaborative analysis of 18 prospective studies. J Natl Cancer Inst. 2008;100:170-183.

88. Morgentaler A. Testosterone replacement therapy and prostate cancer. Urol Clin North Am. 2007;34:555-563, vii.

89. Khera M. Androgens and erectile function: a case for early androgen use in postprostatectomy hypogonadal men. J Sex Med. 2009;6 Suppl. 3: 234-238.

90. Coward RM, Simhan J, Carson CC 3rd. Prostate-specific antigen changes and prostate cancer in hypogonadal men treated with testosterone replacement therapy. BJU Int. 2009;103:1179-1183.

91. Rhoden EL, Morgentaler A. Risks of testosterone-replacement therapy and recommendations for monitoring. N Engl J Med. 2004;350:482-492.

92. Morales A, Lunenfeld B. Investigation, treatment and monitoring of late-onset hypogonadism in males. Official recommendations of ISSAM. International Society for the Study of the Aging Male. Aging Male. 2002;5:74-86.

93. Sarosdy MF. Testosterone replacement for hypogonadism after treatment of early prostate cancer with brachytherapy. Cancer. 2007;109:536-541.

94. Morales A, Black AM, Emerson LE. Testosterone administration to men with testosterone deficiency syndrome after external beam radiotherapy for localized prostate cancer: preliminary observations. BJU Int. 2009;103:62-64.

95. Samaras N, Frangos E, Forster A, Lang P, Samaras D. Andropause: a review of the definition and treatment. Eur Geriatr Med. 2012;3(6):368-373.
96. Samaras N, Samaras D, Lang PO, et al. [Chronic obstructive pulmonary disease: risk and benefit of testosterone therapy]. Rev Med Suisse. 2012;8:2224-2227.

97. Davis SR, Panjari M, Stanczyk FZ. Clinical review: DHEA replacement for postmenopausal women. J Clin Endocrinol Metab. 2011;96:1642-1653.

98. Panjari M, Davis SR. DHEA for postmenopausal women: a review of the evidence. Maturitas. 2010;66:172-179.

99. Liu D, Dillon JS. Dehydroepiandrosterone stimulates nitric oxide release in vascular endothelial cells: evidence for a cell surface receptor. Steroids. 2004;69:279-289.

100. Valenti G, Denti L, Maggio M, et al. Effect of DHEAS on skeletal muscle over the life span: the InCHIANTI study. J Gerontol A Biol Sci Med Sci. 2004;59:466-472.

101. Kostka T, Arsac LM, PatricotMC, Berthouze SE, Lacour JR, Bonnefoy M. Leg extensor power and dehydroepiandrosterone sulfate, insulin-like growth factor-I and testosterone in healthy active elderly people. Eur J Appl Physiol. 2000;82:83-90.

102. Ravaglia G, Forti P, Maioli F, et al. Determinants of functional status in healthy Italian nonagenarians and centenarians: a comprehensive functional assessment by the instruments of geriatric practice. $\mathrm{J} \mathrm{Am}$ Geriatr Soc. 1997;45:1196-1202.

103. Bischoff-Ferrari HA, Orav EJ, Dawson-Hughes B. Additive benefit of higher testosterone levels and vitamin D plus calcium supplementation in regard to fall risk reduction among older men and women. Osteoporos Int. 2008;19:1307-1314.

104. Nawata H, Tanaka S, Takayanagi R, et al. Aromatase in bone cell: association with osteoporosis in postmenopausal women. J Steroid Biochem Mol Biol. 1995;53:165-174.

105. Wang L, Wang YD, Wang WJ, Zhu Y, Li DJ. Dehydroepiandrosterone improves murine osteoblast growth and bone tissue morphometry via mitogen-activated protein kinase signaling pathway independent of either androgen receptor or estrogen receptor. $J$ Mol Endocrinol. 2007;38:467-479.

106. Clarke BL, Ebeling PR, Jones JD, et al. Predictors of bone mineral density in aging healthy men varies by skeletal site. Calcif Tissue Int. 2002;70:137-145.

107. Barrett-Connor E, Goodman-Gruen D, Patay B. Endogenous sex hormones and cognitive function in older men. $J$ Clin Endocrinol Metab. 1999;84:3681-3685.

108. Michael A, Jenaway A, Paykel ES, Herbert J. Altered salivary dehydroepiandrosterone levels in major depression in adults. Biol Psychiatry. 2000;48:989-995.

109. Feldman HA, Johannes CB, Araujo AB, Mohr BA, Longcope C, McKinlay JB. Low dehydroepiandrosterone and ischemic heart disease in middle-aged men: prospective results from the Massachusetts Male Aging Study. Am J Epidemiol. 2001;153:79-89.

110. Yoshida S, Aihara K, Azuma H, et al. Dehydroepiandrosterone sulfate is inversely associated with sex-dependent diverse carotid atherosclerosis regardless of endothelial function. Atherosclerosis. 2010;212:310-315.

111. Herrington DM. Dehydroepiandrosterone and coronary atherosclerosis. Ann N Y Acad Sci. 1995;774:271-280.

112. Herrington DM, Nanjee N, Achuff SC, Cameron DE, Dobbs B, Baughman KL. Dehydroepiandrosterone and cardiac allograft vasculopathy. J Heart Lung Transplant. 1996;15:88-93.

113. Nakamura S, Yoshimura M, Nakayama M, et al. Possible association of heart failure status with synthetic balance between aldosterone and dehydroepiandrosterone in human heart. Circulation. 2004;110:1787-1793.

114. Jankowska EA, Biel B, Majda J, et al. Anabolic deficiency in men with chronic heart failure: prevalence and detrimental impact on survival. Circulation. 2006;114:1829-1837.

115. Shufelt C, Bretsky P, Almeida CM, et al. DHEA-S levels and cardiovascular disease mortality in postmenopausal women: results from the National Institutes of Health-National Heart, Lung, and Blood Institute (NHLBI)-sponsored Women's Ischemia Syndrome Evaluation (WISE). J Clin Endocrinol Metab. 2010;95:4985-4992. 
116. Barrett-Connor E, Khaw KT, Yen SS. A prospective study of dehydroepiandrosterone sulfate, mortality, and cardiovascular disease. $N$ Engl J Med. 1986;315:1519-1524.

117. Basar MM, Aydin G, Mert HC, et al. Relationship between serum sex steroids and Aging Male Symptoms score and International Index of Erectile Function. Urology. 2005;66:597-601.

118. Alexopoulou O, Jamart J, Maiter D, et al. Erectile dysfunction and lower androgenicity in type 1 diabetic patients. Diabetes Metab 2001;27:329-336.

119. Feldman HA, Goldstein I, Hatzichristou DG, Krane RJ, McKinlay JB Impotence and its medical and psychosocial correlates: results of the Massachusetts Male Aging Study. J Urol. 1994;151:54-61.

120. Davis SR, Davison SL, Donath S, Bell RJ. Circulating androgen levels and self-reported sexual function in women. JAMA. 2005;294:91-96.

121. Morales AJ, Haubrich RH, Hwang JY, Asakura H, Yen SS. The effect of six months treatment with a $100 \mathrm{mg}$ daily dose of dehydroepiandrosterone (DHEA) on circulating sex steroids, body composition and muscle strength in age-advanced men and women. Clin Endocrinol (Oxf). 1998;49:421-432.

122. Villareal DT, Holloszy JO, Kohrt WM. Effects of DHEA replacement on bone mineral density and body composition in elderly women and men. Clin Endocrinol (Oxf). 2000;53:561-568.

123. Villareal DT, Holloszy JO. Effect of DHEA on abdominal fat and insulin action in elderly women and men: a randomized controlled trial. JAMA. 2004;292:2243-2248.

124. Kalman DS, Colker CM, Swain MA, Torina GC, Shi Q. A randomized, double-blind, placebo-controlled study of 3-acetyl-7-oxodehydroepiandrosterone in healthy over-weight adults. Curr Ther Res. 2000;61:435-442.

125. Kenny AM, Boxer RS, Kleppinger A, Brindisi J, Feinn R, Burleson JA. Dehydroepiandrosterone combined with exercise improves muscle strength and physical function in frail older women. $J$ Am Geriatr Soc. 2010;58:1707-1714.

126. Weiss EP, Shah K, Fontana L, Lambert CP, Holloszy JO, Villareal DT. Dehydroepiandrosterone replacement therapy in older adults: 1- and 2-y effects on bone. Am J Clin Nutr. 2009;89:1459-1467.

127. von Muhlen D, Laughlin GA, Kritz-Silverstein D, Bergstrom J, Bettencourt R. Effect of dehydroepiandrosterone supplementation on bone mineral density, bone markers, and body composition in older adults: the DAWN trial. Osteoporos Int. 2008;19:699-707.

128. Jankowski CM, Gozansky WS, Schwartz RS, et al. Effects of dehydroepiandrosterone replacement therapy on bone mineral density in older adults: a randomized, controlled trial. J Clin Endocrinol Metab. 2006;91:2986-2993.

129. Jankowski CM, Gozansky WS, Kittelson JM, Van Pelt RE, Schwartz RS, Kohrt WM. Increases in bone mineral density in response to oral dehydroepiandrosterone replacement in older adults appear to be mediated by serum estrogens. J Clin Endocrinol Metab. 2008;93:4767-4773.

130. Labrie F, Diamond P, Cusan L, Gomez JL, Belanger A, Candas B. Effect of 12-month dehydroepiandrosterone replacement therapy on bone, vagina, and endometrium in postmenopausal women. J Clin Endocrinol Metab. 1997;82:3498-3505.

131. Sun Y, Mao M, Sun L, Feng Y, Yang J, Shen P. Treatment of osteoporosis in men using dehydroepiandrosterone sulfate. Chin Med $J$ (Engl). 2002;115:402-404.

132. Nair KS, Rizza RA, O'Brien P, et al. DHEA in elderly women and DHEA or testosterone in elderly men. $N$ Engl J Med. 2006;355: 1647-1659.

133. Schmidt PJ, Daly RC, Bloch M, et al. Dehydroepiandrosterone monotherapy in midlife-onset major and minor depression. Arch Gen Psychiatry. 2005;62:154-162.

134. Wolkowitz OM, Reus VI, Keebler A, et al. Double-blind treatment of major depression with dehydroepiandrosterone. Am J Psychiatry. 1999;156:646-649

135. Wolkowitz OM, Reus VI, Roberts E, et al. Dehydroepiandrosterone (DHEA) treatment of depression. Biol Psychiatry. 1997;41: 311-318.
136. Strous RD, Maayan R, Lapidus R, et al. Dehydroepiandrosterone augmentation in the management of negative, depressive, and anxiety symptoms in schizophrenia. Arch Gen Psychiatry. 2003;60: 133-141

137. Bloch M, Schmidt PJ, Danaceau MA, Adams LF, Rubinow DR. Dehydroepiandrosterone treatment of midlife dysthymia. Biol Psychiatry. 1999;45:1533-1541.

138. Reiter WJ, Pycha A, Schatzl G, et al. Dehydroepiandrosterone in the treatment of erectile dysfunction: a prospective, double-blind, randomized, placebo-controlled study. Urology. 1999;53:590-594.

139. Baulieu EE, Thomas G, Legrain S, et al. Dehydroepiandrosterone (DHEA), DHEA sulfate, and aging: contribution of the DHEAge Study to a sociobiomedical issue. Proc Natl Acad Sci U S A. 2000;97:4279-4284.

140. Genazzani AR, Stomati M, Valentino V, et al. Effect of 1-year, lowdose DHEA therapy on climacteric symptoms and female sexuality. Climacteric. 2011;14:661-668.

141. Arlt W, Callies F, van Vlijmen JC, et al. Dehydroepiandrosterone replacement in women with adrenal insufficiency. $N$ Engl J Med. 1999;341:1013-1020.

142. Munarriz R, Talakoub L, Flaherty E, et al. Androgen replacement therapy with dehydroepiandrosterone for androgen insufficiency and female sexual dysfunction: androgen and questionnaire results. $J \mathrm{Sex}$ Marital Ther. 2002;28 Suppl. 1:165-173.

143. Labrie F, Archer D, Bouchard C, et al. Effect of intravaginal dehydroepiandrosterone (Prasterone) on libido and sexual dysfunction in postmenopausal women. Menopause. 2009;16:923-931.

144. Reiter WJ, Schatzl G, Mark I, Zeiner A, Pycha A, Marberger M. Dehydroepiandrosterone in the treatment of erectile dysfunction in patients with different organic etiologies. Urol Res. 2001;29:278-281.

145. Stomati M, Monteleone P, Casarosa E, et al. Six-month oral dehydroepiandrosterone supplementation in early and late postmenopause. Gynecol Endocrinol. 2000;14:342-363.

146. Labrie F, Archer D, Bouchard C, et al. Intravaginal dehydroepiandrosterone (Prasterone), a physiological and highly efficient treatment of vaginal atrophy. Menopause. 2009;16:907-922.

147. Legrain S, Massien C, Lahlou N, et al. Dehydroepiandrosterone replacement administration: pharmacokinetic and pharmacodynamic studies in healthy elderly subjects. J Clin Endocrinol Metab. 2000; 85:3208-3217.

148. Traish AM, Kang HP, Saad F, Guay AT. Dehydroepiandrosterone (DHEA): a precursor steroid or an active hormone in human physiology. J Sex Med. 2011;8:2960-2982.

149. Schwartz AG, Pashko LL. Cancer prevention with dehydroepiandrosterone and non-androgenic structural analogs. J Cell Biochem Suppl. $1995 ; 22: 210-217$.

150. Schwartz AG, Pashko LL. Dehydroepiandrosterone, glucose-6phosphate dehydrogenase, and longevity. Ageing Res Rev. 2004; 3:171-187

151. Allen NE, Appleby PN, Kaaks R, Rinaldi S, Davey GK, Key TJ. Lifestyle determinants of serum insulin-like growth-factor-I (IGF-I), $\mathrm{C}$-peptide and hormone binding protein levels in British women. Cancer Causes Control. 2003;14:65-74

152. Giordano R, Bonelli L, Marinazzo E, Ghigo E, Arvat E. Growth hormone treatment in human ageing: benefits and risks. Hormones (Athens). 2008; 7:133-139.

153. Ghigo E, Arvat E, Gianotti L, et al. Human aging and the GH-IGF-I axis. J Pediatr Endocrinol Metab. 1996;9 Suppl. 3:271-278.

154. Hersch EC, Merriam GR. Growth hormone (GH)-releasing hormone and GH secretagogues in normal aging: Fountain of Youth or Pool of Tantalus? Clin Interv Aging. 2008;3:121-129.

155. Bartke A, Coschigano K, Kopchick J, et al. Genes that prolong life: relationships of growth hormone and growth to aging and life span. J Gerontol A Biol Sci Med Sci. 2001;56:B340-B349.

156. Holzenberger M, Dupont J, Ducos B, et al. IGF-1 receptor regulates lifespan and resistance to oxidative stress in mice. Nature. 2003;421: $182-187$ 
157. Bartke A. Minireview: role of the growth hormone/insulin-like growth factor system in mammalian aging. Endocrinology. 2005; 146:3718-3723.

158. Guevara-Aguirre J, Balasubramanian P, Guevara-Aguirre M, et al. Growth hormone receptor deficiency is associated with a major reduction in pro-aging signaling, cancer, and diabetes in humans. Sci Transl Med. 2011;3:70ra13.

159. Laron $Z$. Do deficiencies in growth hormone and insulin-like growth factor-1 (IGF-1) shorten or prolong longevity? Mech Ageing Dev. 2005;126:305-307.

160. Menezes Oliveira JL, Marques-Santos C, Barreto-Filho JA, et al. Lack of evidence of premature atherosclerosis in untreated severe isolated growth hormone $(\mathrm{GH})$ deficiency due to a GH-releasing hormone receptor mutation. J Clin Endocrinol Metab. 2006;91:2093-2099.

161. Shechter M, Ginsberg S, Scheinowitz M, Feinberg MS, Laron Z. Obese adults with primary growth hormone resistance (Laron syndrome) have normal endothelial function. Growth Horm IGF Res. 2007;17: $165-170$.

162. Shevah O, Laron Z. Patients with congenital deficiency of IGF-I seem protected from the development of malignancies: a preliminary report. Growth Horm IGF Res. 2007; 17:54-57.

163. Besson A, Salemi S, Gallati S, et al. Reduced longevity in untreated patients with isolated growth hormone deficiency. J Clin Endocrinol Metab. 2003;88:3664-3667.

164. Merriam GR, Schwartz RS, Vitiello MV. Growth hormone-releasing hormone and growth hormone secretagogues in normal aging. Endocrine. 2003;22:41-48.

165. Gazzaruso C, Gola M, Karamouzis I, Giubbini R, Giustina A. Cardiovascular risk in adult patients with growth hormone $(\mathrm{GH})$ deficiency and following substitution with GH: an update. J Clin Endocrinol Metab. 2014;99:18-29.

166. Rucker D, Ezzat S, Diamandi A, Khosravi J, Hanley DA. IGF-I and testosterone levels as predictors of bone mineral density in healthy, community-dwelling men. Clin Endocrinol (Oxf). 2004;60:491-499.

167. Gillberg P, Olofsson H, Mallmin H, Blum WF, Ljunghall S, Nilsson AG. Bone mineral density in femoral neck is positively correlated to circulating insulin-like growth factor (IGF)-I and IGF-binding protein (IGFBP)-3 in Swedish men. Calcif Tissue Int. 2002;70:22-29.

168. Schneider HJ, Pagotto U, Stalla GK. Central effects of the somatotropic system. Eur J Endocrinol. 2003;149:377-392.

169. Nyberg F, Burman P. Growth hormone and its receptors in the central nervous system: location and functional significance. Horm Res. 1996;45:18-22.
170. Kalmijn S, Janssen JA, Pols HA, Lamberts SW, Breteler MM. A prospective study on circulating insulin-like growth factor I (IGF-I), IGF-binding proteins, and cognitive function in the elderly. $J$ Clin Endocrinol Metab. 2000;85:4551-4555.

171. Rollero A, Murialdo G, Fonzi S, et al. Relationship between cognitive function, growth hormone and insulin-like growth factor I plasma levels in aged subjects. Neuropsychobiology. 1998;38:73-79.

172. Papadakis MA, Grady D, Black D, et al. Growth hormone replacement in healthy older men improves body composition but not functional ability. Ann Intern Med. 1996;124:708-716.

173. Franco C, Brandberg J, Lonn L, Andersson B, Bengtsson BA, Johannsson $\mathrm{G}$. Growth hormone treatment reduces abdominal visceral fat in postmenopausal women with abdominal obesity: a. 12-month placebo-controlled trial. J Clin Endocrinol Metab. 2005;90:1466-1474.

174. Lange $\mathrm{KH}$, Andersen JL, Beyer N, et al. GH administration changes myosin heavy chain isoforms in skeletal muscle but does not augment muscle strength or hypertrophy, either alone or combined with resistance exercise training in healthy elderly men. J Clin Endocrinol Metab. 2002;87:513-523.

175. de Boer H, Blok GJ, Van der Veen EA. Clinical aspects of growth hormone deficiency in adults. Endocr Rev. 1995;16:63-86.

176. Liu H, Bravata DM, Olkin I, et al. Systematic review: the safety and efficacy of growth hormone in the healthy elderly. Ann Intern Med. 2007;146:104-115.

177. Carro E, Trejo JL, Gerber A, et al. Therapeutic actions of insulin-like growth factor I on APP/PS2 mice with severe brain amyloidosis. Neurobiol Aging. 2006;27:1250-1257.

178. Vitiello MV, Moe KE, Merriam GR, Mazzoni G, Buchner DH, Schwartz RS. Growth hormone releasing hormone improves the cognition of healthy older adults. Neurobiol Aging. 2006;27:318-323.

179. Sathiavageeswaran M, Burman P, Lawrence D, et al. Effects of $\mathrm{GH}$ on cognitive function in elderly patients with adult-onset $\mathrm{GH}$ deficiency: a placebo-controlled 12-month study. Eur J Endocrinol. 2007;156:439-447.

180. Banerjee I, Clayton PE. Growth hormone treatment and cancer risk. Endocrinol Metab Clin North Am. 2007;36:247-263.

181. Bartke A. Growth hormone and aging: a challenging controversy. Clin Interv Aging. 2008;3:659-665.
Clinical Interventions in Aging

\section{Publish your work in this journal}

Clinical Interventions in Aging is an international, peer-reviewed journal focusing on evidence-based reports on the value or lack thereof of treatments intended to prevent or delay the onset of maladaptive correlates of aging in human beings. This journal is indexed on PubMed Central, MedLine,

\section{Dovepress}

CAS, Scopus and the Elsevier Bibliographic databases. The manuscript management system is completely online and includes a very quick and fair peer-review system, which is all easy to use. Visit http://www.dovepress. com/testimonials.php to read real quotes from published authors. 